\title{
Dental and oral health status of an Iranian population of drug abusers: A comparative study
}

\author{
Salmeh Kalbassi ${ }^{1 *}$, Samira Louni Aligoudarzi ${ }^{2}$, Vahid Asgary ${ }^{3}$ \\ ${ }^{1}$ Kowsar Charity Clinic, ${ }^{2}$ Mehr Medical Laboratory, ${ }^{3}$ Department of Immunology, School of Medicine, Tehran University of \\ Medical Sciences, Tehran, Iran
}

*For correspondence: Email: Kalbassi_salmeh@yahoo.com; Tel: +9866176745

\begin{abstract}
Purpose: To evaluate the effects of hallucinogens, opioids and methamphetamines abuse on oral and dental health of an Iranian population.

Methods: In this descriptive cross sectional survey conducted in 2017, 500 drug abusers referred to addiction rehabilitation centers in Tehran Province in Tehran were selected as the study population. A questionnaire was developed to evaluate demographic data, self-reported oral health experiences during periods of substance abuse and details of substance abuse including types of substances abused, patterns and period of substance abuse.

Results: After excluding 23 addicts due to incomplete data, 500 peoples participated. Of the 500 included subjects, 390 (88 \%) were male and 110 (22\%) were female. As for the qualitative variables the differences were found to be significant for route of abuse $(p<0.001)$, smoking $(p<0.03)$, pain $(p<$ $0.001)$ and abnormal sounds ( $p<0.001)$ of TMJ, sensitivity of chewing muscles $(p=0.002)$, smoking melanosis $(p<0.05)$, hypertrophic lesions $(p=0.01)$ and bleeding on probing $(p=0.001)$.

Conclusion: The findings reveal the poor dental and oral health status of drug addicts in Iran, especially methamphetamine abusers. Therefore, the results call for the design and implementation of oral health improvement programs for addicts in Iran.
\end{abstract}

Keywords: Drug abuse, Dental health, Addicts, Hypertrophic lesions, Chewing muscles, Smoking melanosis, Methamphetamine

\begin{abstract}
This is an Open Access article that uses a funding model which does not charge readers or their institutions for access and distributed under the terms of the Creative Commons Attribution License (http://creativecommons.org/licenses/by/4.0) and the Budapest Open Access Initiative (http://www.budapestopenaccessinitiative.org/read), which permit unrestricted use, distribution, and reproduction in any medium, provided the original work is properly credited.

Tropical Journal of Pharmaceutical Research is indexed by Science Citation Index (SciSearch), Scopus, International Pharmaceutical Abstract, Chemical Abstracts, Embase, Index Copernicus, EBSCO, African Index Medicus, JournalSeek, Journal Citation Reports/Science Edition, Directory of Open Access Journals (DOAJ), African Journal Online, Bioline International, Open-J-Gate and Pharmacy Abstracts
\end{abstract}

\section{INTRODUCTION}

Drug abuse is one of the world's most overwhelming health problems; it can be considered as a predominant problem, especially in Iran. In 2015, substances abuse-related conditions resulted in 307,400 deaths compared to 165,000 deaths in twenty years ago. Among these, the highest numbers were from alcohol abuse-related disorders, which caused 137,500 deaths; opioid abuse-related disorders caused 122,100 deaths, amphetamine abuse-related disorders caused 12,200 deaths, and cocaine abuse disorders caused 11,100 [1,2].

Iran, located along the trade route of illegal drugs (the borders of Afghanistan), has one of the highest rates of drug addiction. Iranian health 
ministry official report estimate there are more than two million substance addicts in this country of 80 million, constituting $2.75 \%$ of the population. Substance abuse and its consequences impose a heavy burden on the individual and take a heavy toll in terms of severe health complications, dangerous behavior, violence, and social complications. The direct complications of substance abuse include, respiratory dysfunction, cirrhosis, cardiac crisis, infectious diseases such as AIDS, sepsis, leprosy, impetigo and endocarditis, nephropathy, and psychological complications such as melancholia as well as oral and dental health problems [3-5]. Oral health complications are among the most frequent health concerns associated with substance dependence. Many studies state that substance abuse can lead to periodontal diseases, dental caries, pathologic lesions, issues in teeth mobility, and missing teeth. In addition, there are other side effects and lifestyle factors such as the frequent consumption of sugary and fizzy drinks, xerostomia, bruxism, dental attrition, infrequent oral hygiene, and the destructive nature of some drugs that exacerbate the dental and oral health in drug abusers $[6,7]$.

Meth mouth is an irreversible and incurable tooth decay that causes loss of teeth, xerostomia, bruxism, and other oral complications that are potentially symptomatic of the prolonged use of the substance methamphetamine. In addition, the most outstanding consequence of the longterm use of methamphetamine on oro-dental health is the development of tooth decay, in which the teeth of the addict appears to be dark and in the process of decaying. The effects of illicit drugs on oral and dental health have been evaluated in some studies over the recent decades, but only few have assessed the effects of hallucinogens [8-10].

In light of the increasing prevalence of drug abuse involving hallucinogens, opioids, and methamphetamines in Iran, especially among teenagers, and the severe effects of these substances, the aim of the study is to perform a comprehensive evaluation of their effects on the oral and dental health of drug abusers in order to improve the understanding of these complications, which can lead to prevention, early detection, and more effective treatments.

\section{METHODS}

In this descriptive survey conducted in 2017, 500 drug abusers who were referred to the addiction rehabilitation centers in Tehran province were selected as the study population. The required information for the study was gathered by conducting face-to-face interviews with all the subjects, along with a thorough physical examination of their oral cavity.

\section{Study subjects}

The participants were recruited from the clinics of the metropolis of Tehran as its population represents a proper example for this study. Recognizing the substance addicts in the general population can be challenging while facing additional challenges like cooperation and compliance. This problem was solved by recruiting the subjects from the addiction treatment centers. The study has been confirmed by the ethical committee of Iran University of Medical Sciences (ref no. 128695/87). Written informed consent was obtained from each participant, and the study was carried out in accordance with the principles of the Declaration of Helsinki [11]. In the study, 500 drug addicts volunteered to participate in the investigation. Altogether, 15 clinics were selected for the survey.

\section{Data collection}

A comprehensive form was developed to evaluate the demographic data, self-declared oral health involvements during the periods of substance abuse, and its details like the types of drugs abused, patterns and the period of substance abuse. Additionally, twelve trained dentists performed clinical examinations to evaluate the dental and oral health status (by fulfilling a check-list) of the participants, and conducted face-to-face interviews with them. If necessary, the contributors were able to ask for further enlightenments regarding the questions. The form requested for data on the oral health behavior (OHB) components based on the earlier confirmed questionnaires [12,13]. Nine trained and calibrated examiners under the standard and regular circumstances, including flat mirror and typical dental light, and blunt explorer, conducted the dental checkup either in private dental clinics or rooms in rehabilitation centers. The temporomandibular joint function, hypoplasia of the first permanent molars, and dental anomalies were reported regarding to the World Health Organization criteria. The dentists explained the goal of the investigation to all volunteers and assured them that the data would be kept confidential.

\section{Statistical analysis}

The results for the variations in oral health were reported as the mean \pm standard deviation (SD) 
for the quantitative variables and as percentages for the categorical variables. The data obtained from the study was analyzed with the help of the SPSS (ver.20) software. The statistically independent $t$ test was used to evaluate the significance of the differences between the two groups (hallucinogenic and non-hallucinogenic drug users) in terms of the mean of the continuous variables, where $p<0.05$ was considered as statistically significant. The upper reference values were defined as 95 percentile of the normal values in each group.

\section{RESULTS}

In this study, after the exclusion 23 participants due to incomplete data, the total number of subjects was 500. Among these 500 subjects, 390 (88 \%) were male and 110 (22 \%) were female. The mean age of the study population was 23.2 years old with the minimum and maximum ages being 18 and 60 years old, respectively. The profile of the group, patterns of drug abuse, and the comparative demographic and clinical characteristics of the participants are summarized in Tables 1, 2 and 3. Out of the 500 participants, 310 were addicted to Methamphetamine (crystal), 26 to 3,4Methylenedioxymethamphetamine (ecstasy), 111 to Cannabis (marijuana i.e., herbal cannabis), 91 to Hashish (cannabis resin), 41 to Lysergic acid diethylamide (LSD), 75 to Opium (poppy tears), 29 to Diamorphine (heroin), and 46 to Crack cocaine (crack). Nearly all the participants were poly-drug users; in addition, 401 (80.2 \%) subjects were active smokers at the time of study.

The differences between the two groups comprising hallucinogen addicts like crystal (Methamphetamine), ecstasy, and LSD and nonhallucinogen abusers like marijuana, hashish, opium, heroin, and crack, respectively, were evaluated. For the qualitative variables, the differences were found to be significant regarding the route of abuse $(p<0.001)$, smoking $(p<$ $0.03)$, pain $(p<0.001)$, abnormal sounds $(p<$ $0.001)$ of TMJ, the sensitivity of the chewing muscles $(p=0.002)$, smoking melanosis $(p<$ $0.05)$, hypertrophic lesions $(p=0.01)$, and bleeding on probing $(p=0.001)$. According to Table 1, the differences were found to be significant for the age, duration of abuse, DMFT indices, GPD, and PI of the crystal abusers, compared with the others.

\section{DISCUSSION}

The Iranian Ministry of Health and Medical Education ranked addiction as the fourth most important health problem in the country. The direct and indirect side-effects of illegal drug abuse on the dental and oral health has rarely been surveyed, probably due to the difficulties in recruiting the appropriate individuals. This challenge can be overcome by concentrating on those who are presently in the drug rehabilitation clinics, as previous studies have done [14,15]. The present study is in accordance with Shekarchizadeh et al, Bourgeois et al and Chen et al regarding the advantages of this method of recruitment of the subjects [14-16].

The results of this investigation revealed poor oral self-care among the addicts. Similar to the other reports, approximately, only $10 \%$ of the participants regularly brushed their teeth at least twice in a day, and $88 \%$ snacked on sugary products daily, either once or more. In the previous studies conducted in Iran, Brazil, and the USA, the addicts undergoing rehabilitation showed similar habits regarding cleaning the teeth, eating, and dental flossing [14]. These results are comparable to the study, though some investigations in China, England, and Netherlands have reported more favorable selfcleaning behaviors among the addicts [16-18].

Table 1: Oral and dental health characteristics between crystal (methamphetamine) abusers and other addicts

\begin{tabular}{|c|c|c|c|c|c|}
\hline \multirow[t]{2}{*}{ Variable } & \multicolumn{2}{|c|}{$\begin{array}{c}\text { Non-crystal } \\
\text { abusers }\end{array}$} & \multicolumn{2}{|c|}{ Crystal addicts } & \multirow[t]{2}{*}{$P$-value } \\
\hline & CV & Mean & CV & Mean & \\
\hline Age & 4.111 & 31.15 & 4.165 & 24.30 & $<0.001$ \\
\hline Abuse Duration (years) & 2.412 & 10.2 & 1.74 & 3.5 & $<0.001$ \\
\hline Mandible's ROM & 3.229 & 44.51 & 3.101 & 33.9 & $<0.001$ \\
\hline decay & 5.001 & 9.82 & 2.102 & 14.98 & $<0.001$ \\
\hline \multirow{2}{*}{$\begin{array}{ll}\text { DMFT } & \text { missing } \\
\text { filled }\end{array}$} & 2.010 & 10.42 & 3.572 & 8.23 & $<0.001$ \\
\hline & 5.267 & 2.41 & 1.742 & 3.38 & $<0.001$ \\
\hline Plaque Index & 4.113 & 77 & 6.005 & 80.11 & 0.001 \\
\hline GPD & 2.332 & 26.549 & 4.631 & 24.96 & 0.03 \\
\hline CPITN & 3.881 & 15.18 & 3.09 & 16.95 & 0.123 \\
\hline & 7.12 & 0.43 & 0.566 & 0.31 & 0.061 \\
\hline $\begin{array}{l}\text { Maximum Mobility } \\
\text { Xerostomia Index }\end{array}$ & 8.521 & 3.37 & 1.036 & 3.67 & 0.049 \\
\hline
\end{tabular}


Table 2: Characteristics of two groups of addicts

\begin{tabular}{|c|c|c|c|c|c|}
\hline \multicolumn{3}{|c|}{$\begin{array}{ll}\text { Variable } \\
\end{array}$} & \multirow{3}{*}{$\begin{array}{c}\begin{array}{c}\text { Non-hallucinogen } \\
(\mathbf{\%})\end{array} \\
10.3 \\
237\end{array}$} & \multirow{2}{*}{$\begin{array}{c}\begin{array}{c}\text { Hallucinogen } \\
\text { (\%) }\end{array} \\
40.6\end{array}$} & \multirow{2}{*}{$\begin{array}{l}\text { P-value } \\
<0.001\end{array}$} \\
\hline & Age (years) & $<23$ & & & \\
\hline & & $23-30$ & & 27.2 & \\
\hline & & $30-40$ & 40.1 & 27.2 & \\
\hline & & $>40$ & 25.9 & 5 & \\
\hline \multirow{2}{*}{\multicolumn{2}{|c|}{ Sex }} & Male & 93.2 & 95.1 & 0.96 \\
\hline & & Female & 6.8 & 4.9 & \\
\hline \multirow{3}{*}{\multicolumn{2}{|c|}{ Frequency of abuse (per day) }} & Once & 8.9 & 19.9 & $<0.02$ \\
\hline & & Twice & 60.2 & 53.8 & \\
\hline & & $\begin{array}{l}3 \text { times or } \\
\text { more }\end{array}$ & 30.9 & 26.3 & \\
\hline \multirow{2}{*}{\multicolumn{2}{|c|}{ Smoking }} & No & 11.3 & 18.3 & $<0.03$ \\
\hline & & Yes & 88.7 & 81.7 & \\
\hline \multirow{4}{*}{\multicolumn{2}{|c|}{ Rout of use drugs }} & Inhalation & 79.2 & 26.4 & $<0.001$ \\
\hline & & Eating & 1.2 & 68.6 & \\
\hline & & Nasal & 4.5 & 2.1 & \\
\hline & & $\begin{array}{l}\text { Intravenous } \\
\text { injection }\end{array}$ & 15.1 & 2.9 & \\
\hline \multirow{2}{*}{\multicolumn{2}{|c|}{ Feeling changes in the oral cavity }} & No & 19.3 & 26.4 & 0.202 \\
\hline & & Yes & 80.7 & 73.6 & \\
\hline \multirow{2}{*}{\multicolumn{2}{|c|}{ Feeling tooth decay }} & No & 29.8 & 24.9 & 0.631 \\
\hline & & Yes & 70.2 & 75.1 & \\
\hline \multirow{2}{*}{\multicolumn{2}{|c|}{ Feeling Changes in chewing }} & No & 36.2 & 33.8 & 0.490 \\
\hline & & Yes & 63.8 & 66.2 & \\
\hline \multirow{2}{*}{\multicolumn{2}{|c|}{ Toothache }} & No & 30.6 & 38.8 & 0.293 \\
\hline & & Yes & 69.4 & 61.2 & \\
\hline \multirow{2}{*}{\multicolumn{2}{|c|}{ TMJ* }} & No & 55.8 & 19.9 & 0.001 \\
\hline & & Yes & 44.2 & 80.1 & \\
\hline \multirow{2}{*}{\multicolumn{2}{|c|}{ Abnormal sounds }} & No & 49.6 & 20.2 & 0.001 \\
\hline & & Yes & 50.4 & 79.8 & \\
\hline & Sensitive & No & 54.1 & 30.5 & 0.002 \\
\hline & muscles & Yes & 45.9 & 69.5 & \\
\hline \multirow{2}{*}{\multicolumn{2}{|c|}{ Pathologic lesions }} & No & 55.3 & 57.9 & 0.502 \\
\hline & & Yes & 44.7 & 42.1 & \\
\hline \multirow{2}{*}{\multicolumn{2}{|c|}{ Aphthous stomatitis }} & No & 75.7 & 83.7 & 0.261 \\
\hline & & Yes & 24.3 & 16.3 & \\
\hline \multirow{2}{*}{\multicolumn{2}{|c|}{ Lichenoid lesions }} & No & 70.3 & 88.1 & 0.298 \\
\hline & & Yes & 29.7 & 11.9 & \\
\hline \multirow{2}{*}{\multicolumn{2}{|c|}{ Smoking Melanosis }} & No & 74.2 & 85.1 & $<0.05$ \\
\hline & & Yes & 25.8 & 14.9 & \\
\hline \multicolumn{2}{|c|}{ Hypertrophic } & No & 88.1 & 90.9 & 0.01 \\
\hline \multicolumn{2}{|c|}{ lesions } & Yes & 11.9 & 9.1 & \\
\hline \multirow{2}{*}{\multicolumn{2}{|c|}{ Spontaneous lesions }} & No & 90 & 80.8 & 0.06 \\
\hline & & Yes & 10 & 19.2 & \\
\hline \multirow{2}{*}{\multicolumn{2}{|c|}{ Dry mouth symptoms }} & No & 23.2 & 4.3 & 0.05 \\
\hline & & Yes & 76.8 & 95.7 & \\
\hline Bleec & $g$ after probing & No & 32.1 & 51.8 & 0.001 \\
\hline & & Yes & 67.9 & 48.2 & \\
\hline Dent & sensitivity to heat and cold & No & 27 & 32.5 & 0.124 \\
\hline & & Yes & 73 & 67.5 & \\
\hline
\end{tabular}

Since most participants had an adequate level of knowledge towards dental and oral healthcare, these results can be attributed to addiction and the influence of drug abuse on the patient's behavior, type of drug and its abuse, age, and the duration of addiction. The dental and oral health status among the methamphetamine abusers (Table 1, Table 2) was much worse than that among the non-methamphetamine drug abusers, as reported for the general Iranian population in the previous studies [19-21] as well as some other investigations around the world $[22,23]$. The present study shows a high predominance of TMJ disorders in the methamphetamine abusers as compared to the non-methamphetamine addicts. TMJ disorders can be attributed to the effect of methamphetamine on saliva (decreasing salivary flow), which results to enamel erosion, periodontal disease, and temporomandibular disorders [8-10]. The DMFT of the examined addicts showed a significant difference between 
the methamphetamine and none methamphetamine abusers. The low DMFT score was associated with toothpaste use and the frequency of brushing the teeth. In addition, based on the previous local investigations, the DMFT score among our subjects (22.6) was much higher than that among the general Iranian population [24-26]. These results can be attributed to the acidic and corrosive properties of methamphetamine that affect the teeth [10], and the impurities in the drugs from the production processes [27].

\section{Limitations of the study}

The survey encountered some unavoidable limitations. First, we derived some data regarding oral health experiences from participants' selfreports and brief oral assessments. In addition, it is possible that individuals have a history of alcohol or multidrug use without a corresponding diagnosis in the participant's data.

\section{CONCLUSION}

The findings of this study reveal the poor dental and oral health status of the addicts, especially methamphetamine abusers. Thus, there is a need to design and implement oral health improvement programs for drug addicts in Iran.

\section{DECLARATIONS}

\section{Acknowledgement}

The authors are grateful to the staff of healthcare facilities involved in this study for support. No sources of funding was received for this study.

\section{Conflict of interest}

The authors declare that no competing interests exist with regard to this study.

\section{Contribution of authors}

We declare that this work was done by the author(s) named in this article and all liabilities pertaining to claims relating to the content of this article will be borne by the authors, Conceived and designed the experiments: SK; collected and analysed the data: SK, SLA; VA; Wrote the manuscript: VA, SLA. All authors read and approved the manuscript for publication.

\section{REFERENCES}

1. McHugh RK, Nielsen S, Weiss RD. Prescription drug abuse: from epidemiology to public policy. J Subst
Abuse Treat 2015; 48: 1-7.

2. Sun H-q, Bao Y-p, Zhou S-j, Meng S-q, Lu L. The new pattern of drug abuse in China. Curr Opin Psychiatry 2014; 27: 251-255.

3. McFall AM, Solomon SS, Lucas GM, Celentano DD, Srikrishnan AK, Kumar MS, Mehta SH. Epidemiology of HIV and hepatitis $C$ infection among women who inject drugs in Northeast India: a respondent-driven sampling study. Addiction 2017; 112: 1480-1487.

4. Aceijas C, Stimson GV, Hickman M, Rhodes T. Global overview of injecting drug use and HIV infection among injecting drug users. AIDS 2004; 18: 2295-303.

5. Metzger DS, Navaline H, Woody GE. Drug abuse treatment as AIDS prevention. Public Health Rep 1998; 113: 97-106.

6. Baumbauer KM, Young EE, Starkweather AR, Guite JW, Russell BS, Manworren RC. Managing Chronic Pain in Special Populations with Emphasis on Pediatric, Geriatric, and Drug Abuser Populations. Med Clin North Am 2016; 100: 183-197.

7. Tsay W, Hsu J, Kang J, Lan Y-C, Hser Y, Ho I. The substance and illicit drug abuser migration from urban to rural area in Taiwan population between 2005 and 2009. Drug Alcohol Depend 2014; 140:e228.

8. Donaldson $M$, Goodchild $J H$. Oral health of the methamphetamine abuser. Am J Health Syst Pharm 2006; 63: 2078-2082.

9. Laslett AM, Dietze P, Dwyer R. The oral health of street-recruited injecting drug users: prevalence and correlates of problems. Addiction 2008; 103: 1821-1825.

10. De-Carolis C, Boyd G-A, Mancinelli L, Pagano S, Eramo S. Methamphetamine abuse and "meth mouth" in Europe. Med Oral Patol Oral Cir Bucal 2015; 20: e205210.

11. World Medical Association. World Medical Association Declaration of Helsinki: ethical principles for medical research involving human subjects. http://www.wma.net/e/policy/b3.htm. 2008.

12. Bourgeois DM, Llodra J. Health surveillance in EuropeEuropean global oral health indicators development project. Paris: Quintessence International. 2004. ISBN 2-912550-31-39.

13. Chen M-s, Andersen R, Barmes DE, Leclerq M, Lyttle C. Comparing oral health care systems: a second international collaborative study. Comparing oral health care systems: a second international collaborative study 1997.

14. Shekarchizadeh H, Khami MR, Mohebbi SZ, Virtanen Jl. Oral health behavior of drug addicts in withdrawal treatment. BMC oral health 2013; 13: 11.

15. Manarte $P$, Manso MC, Souza D, Frias-Bulhosa J, Gago S. Dental erosion in alcoholic patients under addiction rehabilitation therapy. Med Oral Patol Oral Cir Bucal 2009; 14: e376-383.

16. McKenna G, Madden J, Manton S, Cronin M. Survey of oral health behaviors of patients receiving methadone therapy at a drug rehabilitation centre. J Theory Pract Dent Public Health 2013; 1: 6-13. 
17. Ma H, Shi X-c, Hu D-y, Li X. The poor oral health status of former heroin users treated with methadone in a Chinese city. Med Sci Monit 2012; 18: PH51-55.

18. Molendijk B, Horst GT, Kasbergen M, Truin GJ, Mulder J. Dental health in Dutch drug addicts. Community Dent Oral Epidemiol 1996; 24: 117-119.

19. Bayat F, Vehkalahti MM, Tala H, Zafarmand AH. Dental attendance by insurance status among adults in Tehran, Iran. Int Dent J 2006; 56: 338-344.

20. Yazdani $R$, Vehkalahti MM, Nouri M, Murtomaa $H$. School-based education to improve oral cleanliness and gingival health in adolescents in Tehran, Iran. Int $\mathrm{J}$ Paediatr Dent 2009; 19: 274-281.

21. Bayat F, Vehkalahti MM, Zafarmand AH, Tala H. Impact of insurance scheme on adults' dental check-ups in a developing oral health care system. Eur J Dent 2008; 2: 3-10.

22. Murray C, Densie IK, Morgan C. Dental attendance, perceptions of cost and self-care of school year 12 and
13 students: $A$ focus on Southland, New Zealand. N Z Dent J 2015; 111: 133-141.

23. Chrisopoulos S, Harford JE \& Ellershaw A 2016. Oral health and dental care in Australia: key facts and figures 2015. Cat. no. DEN 229. Canberra: AIHW

24. Motlagh MG, Kohestani A. An investigation on DMFT and DMFS of first permanent molars in 12-year-old blind children in residential institutes for blinds in Tehran (2000-2001). J Dent (Tehran) 2004; 1: 56-61.

25. Hessari H, Vehkalahti MM, Eghbal MJ, Murtomaa HT. Oral health among 35-to 44-year-old Iranians. Med Princ Pract 2007; 16: 280-285

26. Hessari $H$, Vehkalahti MM, Eghbal MJ, Samadzadeh $H$, Murtomaa HT. Oral health and treatment needs among 18-year-old Iranians. Med Princ Pract 2008; 17: 302307.

27. Wright J, Edwards J, Walker S. Exposures associated with clandestine methamphetamine drug laboratories in Australia. Rev Environ Health 2016; 3: 329-352. 